\title{
Diversidade genética em cultivares de arroz e correlações entre caracteres agronômicos
}

\author{
Adeliano Cargnin ${ }^{1 *}$, Moacil Alves de Souza ${ }^{2}$, Adérico Júnior Badaró Pimentel ${ }^{3}$, Cláudia Martellet Fogaça ${ }^{4}$
}

\section{RESUMO}

O objetivo deste trabalho foi estimar as correlações genotípicas entre caracteres e investigar a diversidade genética de cultivares de arroz mais utilizados em cultivo no período de 1950 a 2001 . Foram conduzidos dois experimentos de campo, nas localidades denominadas Aeroporto e Agronomia, ambas pertencentes à Universidade Federal de Viçosa, em Viçosa, MG, no delineamento de blocos ao acaso com três repetições e 25 cultivares. Foram coletados e analisados os dados referentes à produção de grãos, a altura das plantas, dias para a floração, estande inicial, estande final, perfilhamento útil, grãos por panícula, percentagem de espiguetas estéreis por panícula e peso do grão. Verificou-se que as correlações genotípicas foram altas para a maioria dos pares de caracteres. Os caracteres que mais influenciaram a produtividade foram grãos por panícula, percentagem de grãos estéreis e peso do grão. Os cultivares Guarani e Bico Ganga foram os mais divergentes geneticamente e os cultivares Amarelão e IAC 25, os mais similares.

Palavras-chave: Oryza sativa L., variabilidade, seleção, melhoramento.

\section{ABSTRACT}

\section{Genetic diversity in rice cultivars and correlations between agronomic traits}

The objective of this study was to estimate the genotypic correlation between traits and study the genetic diversity of the most cultivated rice cultivars between 1950 and 2001. Two field experiments were conducted at the experimental fields known as Airport and Agronomy, both belong to the Federal University of Viçosa, in Viçosa, MG. The experiments were arranged in a randomized block design with three replications and 25 cultivars. Data on grain yield, plant height, days to flowering, initial stand, final stand, useful tillering, grains per panicle, percentage of sterile spikelets or ears per panicle, and grain weight were collected and analyzed. It was verified high genotypic correlations for most trait pairs. The traits with strongest influence on yield were grains per panicle, percentage of sterile grains and grain weight. The cultivars Guarani and Bico Ganga were the most genetically divergent and cultivars Amarelão and IAC 25 the most similar.

Key words: Oryza sativa L., variability, selection, improvement.

\footnotetext{
Recebido para publicação em abril de 2007 e aprovado em julho de 2009

${ }^{1}$ Engenheiro-Agrônomo, Doutor. Embrapa Cerrados, BR 020 km 18 Rodovia Brasília/Fortaleza, caixa postal 08223, 73310-970, Planaltina, Distrito Federal (DF), Brasil, adeliano@cpac.embrapa.br*Autor para correspondência.

${ }^{2}$ Engenheiro-Agrônomo, Doutor. Universidade Federal de Viçosa (UFV), Departamento de Fitotecnia (DFT), Viçosa, Minas Gerais (MG) Brasil, moacil@ufv.br

${ }^{3}$ Engenheiro-Agrônomo. Universidade Federal de Viçosa (UFV), Departamento de Fitotecnia (DFT), Viçosa, Minas Gerais (MG) Brasil, adericopimentelufv@yahoo.com.br

${ }^{4}$ Bióloga, Doutora. Embrapa Cerrados, Planaltina, DF, Brasil, claudia.fogaca@cpac.embrapa.br
} 


\section{INTRODUÇÃO}

Um dos objetivos básicos dos programas de melhoramento é a obtenção de cultivares mais produtivas. A produtividade é um caráter complexo e resultante da expressão e associação de diferentes componentes. O conhecimento do grau dessa associação, por meio de estudos de correlações, possibilita identificar caracteres que podem ser usados como critério de seleção indireta para a produtividade.

O conhecimento da associação entre caracteres é de grande importância nos trabalhos de melhoramento. A correlação, que pode ser diretamente mensurada a partir de medidas de dois caracteres em certo número de indivíduos da população, é a fenotípica, que tem causas genéticas e ambientais. A correlação genética é devida ao pleiotropismo e desequilíbrio de ligações gênicas, que são causas transitórias, especialmente em populações derivadas de cruzamentos entre linhagens divergentes (Falconer, 1981).

Da mesma forma, os estudos a respeito da diversidade genética apresentam grande relevância no melhoramento de plantas, por fornecerem parâmetros para identificação de genitores que, quando cruzados, possibilitam o desenvolvimento de cultivares superiores, além de facilitarem o conhecimento da base genética da população. Segundo Falconer (1981), a variabilidade genética de uma população segregante depende da diversidade genética entre os pais envolvidos nos cruzamentos.

No estudo da diversidade genética, o grau de dissimilaridade entre os indivíduos dentro ou entre espécies, ou entre genótipos dentro de uma população melhorada, pode ser estimado por meio de técnicas multivariadas, como: análise de componentes principais, variáveis canônicas e análise de agrupamento (Cruz \& Regazzi, 1997). Nesse contexto, a utilização da teoria da análise multivariada tem-se mostrado promissora, pois permite combinar todas as informações contidas na unidade experimental, de modo que as inferências sejam fundamentadas em um complexo de variáveis (Ferrão et al., 2002). Conforme Cruz \& Regazzi (1997), a análise multivariada é um processo alternativo para a avaliação do grau de similaridade genética entre tratamentos, cujo princípio consiste em resumir um grande número de características em outro menor, facilitando as análises dos dados. Permite, também, conhecer a similaridade entre os indivíduos, por meio de suas distâncias ou de sua dispersão gráfica no espaço bi ou tridimensional, e avaliar a importância de cada variável para a variação total observada entre as unidades amostrais, possibilitando a eliminação das que pouco contribuem para essa variação.

Muitos trabalhos de melhoramento vegetal vêm empregando técnicas multivariadas no estudo da diversida- de genética, como o de Cruz (1990) e Fuzatto et al. (2002), em milho; Morais (1992) e Pereira (1999), em arroz; Vidigal et al. (2001), em mandioca; Coimbra \& Carvalho (1998), Ferrão et al. (2002) e Machado et al. (2002), em feijão; Naoe et al. (2001), em soja; e Reis et al. (2001), em trigo.

O objetivo deste trabalho foi estimar as correlações genotípicas entre caracteres e investigar a diversidade genética de cultivares de arroz mais utilizados em cultivo no período de 1950 a 2001.

\section{MATERIAIS E MÉTODOS}

Para a realização deste trabalho, foram utilizados 25 cultivares (Tabela 1), desenvolvidos pelos programas de melhoramento genético do arroz de sequeiro do Brasil, durante o período compreendido entre 1950 e 2001. Foram selecionados os cultivares mais representativas por década de estudo, ou seja, aqueles mais utilizados em lavouras comerciais. Os cultivares foram separados em dois grupos: Grupo Precoces (floração até 90 dias): Amarelão, Batatais, Dourado precoce, Pratão precoce, IAC 25, IAC 165, IAPAR 9, Guarani, Primavera, Carajás, Bonança, CNA 8711 e CNA 8983; e Grupo Tardias (floração acima de 90dias): Pratão, Pérola, Bico Ganga, IAC 1246, IAC 47, Rio Paranaíba, Araguaia, Xingu, Caiapó, Canastra, IAC 202 e Carisma.

Foram conduzidos dois experimentos de campo, nas estações experimentais do Aeroporto e Agronomia, ambas pertencentes à Universidade Federal de Viçosa, em Viçosa, MG. Os experimentos foram conduzidos no delineamento de blocos ao acaso, com três repetições. A parcela experimental foi constituída de cinco fileiras de 5,0 m de comprimento e espaçadas $0,5 \mathrm{~m}$ entre si $\left(12,5 \mathrm{~m}^{2}\right)$, das quais as três linhas centrais foram consideradas como área útil na colheita, eliminando-se 0,5 m em suas extremidades $\left(6 \mathrm{~m}^{2}\right)$. No preparo do solo foram utilizadas, em geral, as práticas convencionais de uma aração e uma ou duas gradagens, de acordo com as necessidades do terreno. A semeadura foi feita dia 15 de dezembro de 2001, colocando-se entre 55 e 60 sementes por metro de sulco. Na adubação de semeadura, utilizaram-se $400 \mathrm{~kg}$. ha- ${ }^{-1} \mathrm{da}$ fórmula 4-14-8, e aos 40 dias, como adubação de cobertura, foram aplicados $40 \mathrm{~kg}$. ha ${ }^{-1}$ de nitrogênio, utilizando-se como fonte o sulfato de amônio.

As parcelas foram colhidas, manualmente, em função do ciclo de cada cultivar, cujos grãos já trilhados foram secados até atingirem $13 \%$ de umidade e, em seguida, beneficiados para a eliminação das impurezas e posterior pesagem. Avaliaram-se na área útil das parcelas, a produção de grãos, a altura das plantas, dias para a floração, estande inicial, estande final, perfilhamento útil, grãos por panícula, percentagem de espiguetas estéreis por panícula e peso do grão. 
Tabela 1 - Genealogia e década de utilização dos cultivares de arroz estudados

\begin{tabular}{|c|c|c|}
\hline Cultivar & Cruzamento & Década \\
\hline 14-Pratão & CULTIVAR TRADICIONAL & Antes 1960 \\
\hline 15-Pérola & CULTIVAR TRADICIONAL & " \\
\hline 1-Amarelão & CULTIVAR TRADICIONAL & ” \\
\hline 16-Bico Ganga & CULTIVAR TRADICIONAL & ” \\
\hline 2-Batatais & CULTIVAR TRADICIONAL & $”$ \\
\hline 3-Dourado Precoce & SELEÇAO MASSAL DO DOURADÃO & $60-70$ \\
\hline 4-Pratão Precoce & SELEÇAO MASSAL DO PRATÃO & " \\
\hline 17-IAC 1246 & PRATÃO/PÉROLA & $”$ \\
\hline 5-IAC 25 & DOURADO PRECOCE/IAC 1246 & $70-80$ \\
\hline 18-IAC 47 & IAC 1246/IAC 1391 & $"$ \\
\hline 6-IAC 165 & DOURADO PRECOCE/IAC 1246 & $”$ \\
\hline 7-IAPAR 9 & IAC F-3-7/BATATAIS & $80-90$ \\
\hline 19-Rio Paranaíba & IAC 47/63-83 & $"$ \\
\hline 8-Guarani & IAC 25/63-83 & ” \\
\hline 20-Araguaia & IAC 47/TOS 2578/7-4-2-3-B2 & ” \\
\hline 21-Xingu & IAC 47/IRAT 13 & ” \\
\hline 22-Caiapó & IRAT 13/BEIRA CAMPO//CNAx104/PÉROLA & $90-2000$ \\
\hline 23-Canastra & TOX 939-107-2-101-1B/(COLOMBIA 1xM 312)//TOX 1780-2-1-1P-4 & " \\
\hline 9-Primavera & IRAT 10/LS 85-158 & ” \\
\hline 24-IAC 202 & LEBONET/IAC25 & ” \\
\hline 10-Carajás & REM 293-B/IAC 81-176 & $”$ \\
\hline 11-Bonança & СТ 7244-9-2-1-52-1/CT 7232-5-3-7-2-1P//CT 6196-33-11-1-3-AP & Depois 2000 \\
\hline 25-Carisma & СT 72244-9-1-5-3/CT 6196-33-11-1-3//CT 6946-2-5-3-3-2-M & " \\
\hline 12-CNA 8711 & CUIABANA/CNAx 1235-8-3//CAN 6673 & $”$ \\
\hline 13-CNA 8983 & KEYBONNET/CAN 7119 & ” \\
\hline
\end{tabular}

A medida da correlação entre duas variáveis, x e y, é obtida pelo estimador do coeficiente de correlação, o qual é fornecido pela divisão do estimador da covariância entre x e y e pela raiz quadrada do produto dos estimadores das variâncias de x e y, ou seja, $r_{x y}=\frac{\operatorname{CÔV}(x, y)}{\sqrt{\hat{V}(x) \cdot \hat{V}(y)}}$. Para a obtenção dos coeficientes de correlações fenotípica, genotípica e de ambiente, entre todos os pares de características estudados neste trabalho, calcularam-se os estimadores das variâncias e covariâncias como apresentado por Cruz \& Regazzi (1997).

Para quantificar a divergência genética entre cultivares, foi utilizada a distância de Mahalanobis $\left(\mathrm{D}_{\mathrm{ii}}^{2}\right.$ ), que considera a correlação residual entre os caracteres. $\mathrm{Na}$ delimitação dos grupos, utilizaram-se a técnica de otimização proposta por Tocher e o método hierárquico do vizinho mais próximo, citados por Cruz \& Regazzi (1997). Todos os procedimentos da análise estatística dos dados experimentais foram realizados com o Programa Genes (Cruz, 2001).

\section{RESULTADOS E DISCUSSÃO}

Para a análise de variância foi feita a decomposição do efeito de cultivares em precoces (floração até 90 dias), tardios (floração acima de 90 dias). Tal procedimento deveu-se ao fato de o arroz de sequeiro ser totalmente dependente das chuvas, que, como ocorrem irregularmente, podem favorecer ou prejudicar mais intensamente um desses grupos de cultivares. Os resultados das análises de variância individuais apresentaram homogeneidade de variância do erro verificada pelo teste de F máximo com valores menores que 3,14, portanto, a análise conjunta foi feita sem qualquer restrição (Tabela 2). Os coeficientes de variação oscilaram entre 2,88\% (peso de grão) e 24,62\% (espiguetas estéreis) conferindo boa precisão aos experimentos, os quais, segundo Lúcio et al. (1999), são classificados como baixo a médio, respectivamente, sendo considerados habituais para tais ensaios agrícolas.

Verificaram-se efeitos significativos para cultivares, locais e para as interações cultivares x locais para todas as características avaliadas (Tabela 2). Isto indica que os cultivares, tanto os precoces como os tardios apresentam respostas diferenciadas quando submetidas a ambientes distintos. Portanto, para maior acurácia das estimativas de correlações entre as características e da diversidade genética entre os cultivares, as análises de tais parâmetros deve ser realizada com base na média dos dois locais a fim de minimizar os efeitos do ambiente na expressão das características. 
Tabela 2 - Quadrados médios, médias e coeficientes de variação (CV\%) das características produção de grãos (PROD), grãos/panícula (GP), espiguetas estéreis (EE), floração (FLO), altura de plantas (AP), estande inicial (EI), estande final (EF), perfilhamento (PF), peso do grão (PG) avaliadas nos ensaios conduzidos nas localidades Aeroporto e Agronomia, em Viçosa, MG, em 2001/02

\begin{tabular}{|c|c|c|c|c|c|c|c|c|c|c|}
\hline \multirow{2}{*}{ Fonte de variação } & \multirow{2}{*}{ GL } & \multicolumn{9}{|c|}{ Quadrado médio } \\
\hline & & PROD & GP & $\mathbf{E E}$ & FLO & AP & EI & EF & PF & PG \\
\hline Cultivares & 24 & $3864726 * *$ & $5665^{* *}$ & $240 * *$ & $492 * *$ & $1314 * *$ & $1189 * *$ & $4477^{* *}$ & $1,98 * *$ & $93 * *$ \\
\hline Grupo das precoces & 12 & $15441094 * *$ & $5928 * *$ & $210 * *$ & $93 * *$ & $1272^{* *}$ & $514 *$ & $4200 * *$ & $0,34^{\mathrm{ns}}$ & $126^{* *}$ \\
\hline Grupo das tardias & 11 & $5298203^{* *}$ & $5602 * *$ & $118^{* *}$ & $101^{* *}$ & $1462^{* *}$ & $2032 * *$ & $3736 * *$ & $3,57 * *$ & $57 * *$ \\
\hline Precoces x Tardias & 1 & $15980062 * *$ & $3199 * *$ & $1956 * *$ & $9585^{* *}$ & $196^{\mathrm{ns}}$ & $9,0^{\mathrm{ns}}$ & $15951^{* *}$ & $4,16^{* *}$ & $89 * *$ \\
\hline Locais & 1 & $121800785^{* *}$ & $13747 *$ & $885^{*}$ & $5,0^{\text {ns }}$ & $25428 * *$ & $21672 * *$ & $214174 * *$ & $1,30^{\mathrm{ns}}$ & $18 *$ \\
\hline Cultivares x Locais & 24 & $2217792 * *$ & $533^{*}$ & $46^{* *}$ & $23 * *$ & $142 * *$ & $437 *$ & $4207 * *$ & $0,51 * *$ & $1,57 * *$ \\
\hline Precoces x Locais & 12 & $511750^{\mathrm{ns}}$ & $434^{\mathrm{ns}}$ & $40 *$ & $17 * *$ & $63^{\text {ns }}$ & $130^{\mathrm{ns}}$ & $2243 *$ & $0,26^{\mathrm{ns}}$ & $0,72^{\mathrm{ns}}$ \\
\hline Tardias x Locais & 11 & $3686060 * *$ & $670^{*}$ & $43 *$ & $21 * *$ & $214 * *$ & $803 * *$ & $5812^{* *}$ & $0,75^{* *}$ & $1,91 *$ \\
\hline Grupos x Locais & 1 & $6539359 * *$ & $203^{\text {ns }}$ & $152 * *$ & $107 * *$ & $291^{*}$ & $104^{\mathrm{ns}}$ & $10113^{* *}$ & $0,90 *$ & $8,07 * *$ \\
\hline Resíduo & 96 & 400377 & 283 & 18 & 6 & 62 & 244 & 1182 & 0,21 & 0,79 \\
\hline \multicolumn{2}{|l|}{ Média Geral } & 4484 & 195 & 17 & 92 & 123 & 106 & 243 & 2,37 & 30,8 \\
\hline \multicolumn{2}{|l|}{ Média Grupo Precoces } & 4798 & 190 & 13 & 84 & 124 & 106 & 234 & 2,21 & 31,6 \\
\hline \multicolumn{2}{|c|}{ Média Grupo Tardias } & 4144 & 199 & 21 & 100 & 122 & 106 & 254 & 2,55 & 30,0 \\
\hline \multicolumn{2}{|c|}{ Coeficiente de Variação (\%) } & 14,10 & 8,63 & 24,62 & 2,86 & 6,40 & 14,65 & 14,09 & 19,32 & 2,88 \\
\hline \multicolumn{2}{|c|}{ Maior QMR/Menor QMR } & 1,07 & 1,32 & 2,13 & 3,14 & 1,04 & 1,00 & 1,63 & 1,22 & 1,20 \\
\hline
\end{tabular}

* e ${ }^{* *}$ significativos a 5 e $1 \%$ de probabilidade, respectivamente e ${ }^{\text {ns }}$ não significativo, pelo teste $\mathrm{F}$.

Analisando as Tabelas 3 e 4, pode-se verificar que, de modo geral, as correlações genotípicas tiveram valores altos para a maioria dos caracteres avaliados. No ensaio do Aeroporto, observou-se, no grupo precoce (Tabela 3), que as correlações genotípicas entre produção de grãos e demais caracteres foram significativas, à exceção do perfilhamento útil, que apresentou valores não significativos. No grupo tardio (Tabela 3), somente os caracteres grãos por panícula, dias até a floração e índice de colheita exibiram correlações genotípicas significativas com produção de grãos. No ensaio da Agronomia (Tabela 4), tanto no grupo precoce quanto no tardio, as correlações ge-

Tabela 3 - Estimativas dos coeficientes de correlações genotípicas entre sete caracteres avaliados de cultivares precoces (acima da diagonal) e tardias (abaixo da diagonal), no ensaio do Aeroporto, em Viçosa, MG, em 2001/02

\begin{tabular}{lccccccc}
\hline Caráter & $\begin{array}{c}\text { Produção } \\
\text { de grãos }\end{array}$ & $\begin{array}{c}\text { Grãos/ } \\
\text { Panícula }\end{array}$ & $\begin{array}{c}\text { Espiguetas } \\
\text { Estéreis }\end{array}$ & $\begin{array}{c}\text { Peso } \\
\text { do Grão }\end{array}$ & $\begin{array}{c}\text { Dias para } \\
\text { Floração }\end{array}$ & $\begin{array}{c}\text { Altura } \\
\text { da Planta }\end{array}$ & $\begin{array}{c}\text { Perfilhamento } \\
\text { Útil }\end{array}$ \\
\hline Produção de grãos & & $0,51^{*}$ & $-0,59^{* *}$ & $-0,54^{*}$ & $0,61^{* *}$ & $-0,81^{* *}$ & 0,30 \\
Grãos/Panícula & $0,61^{* *}$ & & 0,21 & $-0,78^{* *}$ & 0,43 & $-0,35$ & 0,01 \\
Espiguetas Estéreis & $-0,43$ & 0,28 & & $-0,29$ & 0,34 & $-0,26$ & 0,16 \\
Peso do Grão & 0,21 & $-0,46^{*}$ & $-0,41$ & & $-0,75^{* *}$ & $0,67^{* *}$ & $-0,54^{*}$ \\
Dias para Floração & $-0,86^{* *}$ & $-0,61^{* *}$ & $-0,01$ & $0,65^{* *}$ & & $-0,82^{* *}$ & $0,75^{* *}$ \\
Altura das Planta & $-0,42$ & $-0,40$ & $-0,22$ & $0,95^{* *}$ & $0,92^{* *}$ & & $0,91^{* *}$ \\
Perfilhamento Util & 0,21 & $-0,05$ & 0,25 & $-0,51^{*}$ & $-0,67^{* *}$ & $0,95^{* *}$ & \\
\hline
\end{tabular}

* $\mathrm{e}^{* *}$ significativos a 5 e $1 \%$ de probabilidade, pelo teste $\mathrm{t}$, respectivamente.

Tabela 4 - Estimativa dos coeficientes de correlações genotípicas entre sete caracteres avaliados de cultivares precoces (acima da diagonal) e tardias (abaixo da diagonal), no ensaio da Agronomia, em Viçosa, MG, em 2001/02

\begin{tabular}{|c|c|c|c|c|c|c|c|}
\hline Caráter & $\begin{array}{l}\text { Produção } \\
\text { de grãos }\end{array}$ & $\begin{array}{c}\text { Grãos/ } \\
\text { Panícula }\end{array}$ & $\begin{array}{c}\text { Espiguetas } \\
\text { Estéreis }\end{array}$ & $\begin{array}{c}\text { Peso } \\
\text { do Grão }\end{array}$ & $\begin{array}{c}\text { Dias para } \\
\text { Floração }\end{array}$ & $\begin{array}{c}\text { Altura } \\
\text { da Planta }\end{array}$ & $\begin{array}{c}\text { Perfilhamento } \\
\text { Útil }\end{array}$ \\
\hline Produção de grãos & & $-0,24$ & $-0,69 * *$ & $0,66^{* *}$ & $-0,22$ & $-0,16$ & 0,43 \\
\hline Grãos/Panícula & $-0,25$ & & $0,63^{* *}$ & $-0,70 * *$ & $0,57 *$ & $-0,53^{*}$ & $-0,74 * *$ \\
\hline Espiguetas Estéreis & $-0,50 *$ & 0,09 & & $-0,81^{* *}$ & $0,88 * *$ & $-0,64 * *$ & $-0,67 * *$ \\
\hline Peso do Grão & 0,19 & $-0,53^{*}$ & 0,10 & & $-0,93 * *$ & $0,79 * *$ & $0,47^{*}$ \\
\hline Dias para Floração & $-0,29$ & $-0,40$ & 0,25 & 0,42 & & $-0,81 * *$ & $-0,04$ \\
\hline Altura das Planta & 0,25 & $-0,41$ & $-0,01$ & $0,77^{* *}$ & $0,61^{* *}$ & & $0,80^{* *}$ \\
\hline Perfilhamento Util & 0,21 & $0,47^{*}$ & 0,05 & $-0,61 * *$ & $-0,21$ & $-0,71 * *$ & \\
\hline
\end{tabular}

${ }^{*} \mathrm{e}^{* *}$ significativos a 5 e $1 \%$ de probabilidade, pelo teste $\mathrm{t}$, respectivamente.

Rev. Ceres, Viçosa, v. 57, n.1, p. 053-059, jan/fev, 2010 
néticas entre produção de grãos e as demais características foram não significativas, exceto o peso do grão, no grupo precoce.

A produção de grãos na cultura do arroz é uma característica complexa, que é determinada pelos componentes primários: número de panículas $/ \mathrm{m}^{2}$, número de grãos/ panícula, percentagem de grãos cheios e peso do grão. Pode-se notar que no Aeroporto, dentro do grupo precoce, a produção apresentou correlações positiva e significativa com grãos por panícula, negativa e significativa com peso do grão e percentagem de grãos vazios. Para a característica peso do grão, a associação com produção foi de caráter negativo de elevada magnitude no grupo precoce e de baixa magnitude no grupo tardio. Essa característica também está correlacionada negativamente com número de grãos por panícula, o qual explica a associação negativa de produção com peso do grão, já que os cultivares mais produtivos, Primavera e CNA 8983 no grupo precoce, Carisma e IAC 202 no grupo tardio, que apresentaram maior número de grãos por panícula, também tiveram menor peso do grão.

As percentagens de grãos vazios tiveram associação negativa com produção de grãos, tanto no grupo precoce quanto no tardio, sendo no grupo precoce de elevada magnitude e de baixa magnitude no grupo tardio. O índice de colheita exibiu correlações positivas e de elevada magnitude, tanto no grupo precoce quanto no grupo tardio, com produção de grãos e número de grãos por panícula, ressaltando-se que, ainda no ensaio do Aeroporto, os cultivares mais produtivos tanto no grupo precoce (CNA 8983 e Primavera) como no grupo tardio (IAC 202, Carisma, Canastra, Caiapó e Xingu) mostraram maiores índices de colheita. Esse caráter pode ser considerado na seleção de cultivares para o aumento da produção.

A correlação entre ciclo (dias para a floração) e a produção de grãos foi positiva e de elevada magnitude no grupo precoce; no entanto, quando avaliada no grupo tardio, foi negativa e de elevada magnitude. Essa discordância entre os sinais da correlação entre os dois grupos indica que em arroz de sequeiro, pelas diferenças das condições ambientais existentes nas diferentes regiões, os cultivares expressam maior potencial de produção quando sua floração está em torno dos 90 dias. De fato, os cultivares do grupo precoce com menor ciclo (dias até a floração) limitam o tempo de sua permanência no campo, o qual não permite um bom desenvolvimento, provocando reduções em seu rendimento. Por outro lado, os cultivares do grupo tardio com maior número de dias até a floração estão expostas às condições adversas do ambiente, como deficiências hídricas, o que prejudica acentuadamente sua produção.

No ensaio da Agronomia, a característica que mais influenciou a produção de grãos foi o peso do grão, a mesma que teve associação positiva e de elevada magnitude no grupo precoce e de baixa magnitude no grupo tardio, o contrário do ensaio do Aeroporto, em que a correlação entre produção de grãos e peso do grão foi negativa e significativa no grupo precoce e positiva de baixa magnitude no grupo tardio.

Os caracteres percentagem de grãos vazios e dias para a floração estiveram correlacionados negativamente com a produção de grãos nos dois grupos, sendo de elevada magnitude para percentagem de grãos vazios e de baixa magnitude para dias para floração. A correlação entre altura de planta e produção foi negativa e de baixa magnitude no grupo precoce e positiva e de baixa magnitude no grupo tardio. No ensaio da Agronomia, os caracteres que mais influenciaram a produção de grãos foram peso do grão e percentagem de grãos vazios. O caráter perfilhamento útil nos ensaios do Aeroporto e da Agronomia, nos grupos precoce e tardio, esteve correlacionado positivamente com a produção de grãos, mas essa correlação foi de baixa magnitude, não tendo marcada influência na produção de grãos.

A análise da diversidade genética entre os cultivares, com base na distância generalizada de Mahalanobis, constatou-se que os cultivares Guarani e Bico Ganga apresentaram a maior distância (672), o que equivale à maior diversidade genética. No entanto, os cultivares Amarelão e IAC $25(7,52)$ são os mais similares geneticamente.

A maior amplitude da diversidade genética entre os cultivares Guarani e Bico Ganga, avaliada pela distância de Mahalanobis, deve-se ao fato de serem as mais contrastantes nas principais características, como produção de grãos, em que o cultivar Guarani alcançou maior média de produção, com $4.179 \mathrm{~kg}$. ha-1 ${ }^{-1}$ e o Bico Ganga, a menor média, com 1.483 kg. ha-1 .

No que se refere ao ciclo (dias para floração), ambos também se encontravam entre os mais contrastantes, pois o cultivar Guarani é um dos mais precoces, com 78 dias para a floração, e a Bico Ganga, um dos mais tardios, com 105 dias. No entanto, os cultivares Amarelão e IAC 25, indicados como os mais similares pela distância de Mahalanobis, apresentaram-se estáveis e com boa adaptação (produção) nos locais avaliados.

O agrupamento pelo método de Tocher revelou a formação de nove grupos, os quais são apresentados na Tabela 5. O grupo I inclui os cultivares Amarelão, IAC 25, IAC 165, Dourado Precoce, IAPAR 9, Carajás, Batatais e Pratão Precoce; o grupo II, IAC 47, Xingu, Rio Paranaíba, IAC 1246 e Araguaia; o grupo III, Primavera, CNA 8983 e IAC 202; o grupo IV, Pratão, Bico Ganga e Pérola; o grupo V, Bonança e Carisma; e os grupos VI, VII, VIII e IX, um só cultivar cada, Canastra, CNA 8711, Caiapó e Guarani, respectivamente. 
Tabela 5 - Agrupamento dos cultivares de arroz, utilizando-se a distância generalizada de Mahalanobis e o método de otimização de Tocher

\begin{tabular}{ll}
\hline Grupo & \multicolumn{1}{c}{ Cultivar } \\
\hline I & 1: Amarelão; 5: IAC 25; 6: IAC 165; 3: Dourado Precoce; 7: IAPAR 9; 10: Carajás; 2: Batatais; e 4: Pratão Precoce \\
II & 18: IAC 47; 21: Xingu; 19: Rio Paranaíba; 17: IAC 1246; e 20: Araguaia \\
III & 9: Primavera; 13: CNA 8983; 24: IAC 202 \\
IV & 14: Pratão; 16: Bico Ganga; e 15: Pérola \\
V & 11: Bonança; 25: Carisma \\
VI & 23: Canastra \\
VII & 12: CNA 8711 \\
VIII & 22: Caiapó \\
IX & 8: Guarani \\
\hline
\end{tabular}

O grupo I é o mais amplo sendo, constituído por cultivares de maior precocidade, maior altura de planta e maior peso do grão. O grupo II foi formado pelos cultivares IAC 47, Xingu, Rio Paranaíba, IAC 1246 e Araguaia, existindo parentesco entre eles, pois Xingu, Rio Paranaíba e Araguaia são descendentes do cultivar IAC 47 e este do cultivar IAC 1246. O grupo III foi formado por cultivares gerados após a década de 2000, cuja característica principal foi a de possuir grande número de grãos por panícula, grãos de menor peso e plantas mais baixas e de maior perfilhamento, sendo o grupo IV formado pelos cultivares Pratão, Bico Ganga e Pérola, considerados como tradicionais. O grupo $\mathrm{V}$ foi formado pelos cultivares Bonança e Carisma, originários de cruzamentos realizados pelo Centro de Agricultura Tropical CIAT, na Colômbia. Os cultivares Canastra, CNA 8711, Caiapó e Guarani formaram grupos isolados.

Pela Figura 1, relativa ao agrupamento do vizinho mais próximo, observa-se a formação de seis grupos, diferenciando-se do método de Tocher, que formou nove. O primeiro grupo formou-se com os cultivares Amarelão, IAC 25, IAC 165, Dourado Precoce, IAPAR 9, Carajás, Batatais,
Pratão Precoce e Guarani; o II grupo, com os cultivares IAC 47, Xingu, Rio Paranaíba, IAC 1246, Araguaia e Caiapó; o grupo III, com Primavera, CNA 8983, IAC 202 e CNA 8711; o grupo IV, com Pratão, Bico Ganga e Pérola; o grupo V, com Bonança e Carisma; e o grupo VI, com o cultivar Canastra.

Os grupos nos quais se incluíram novos cultivares foram I, II e III. Os grupos IV, V e VI não foram modificados, sendo iguais aos formados pelo método de Tocher.

Para fins de melhoramento, os cultivares de maior valor para serem utilizados em programas de cruzamentos na cultura do arroz de sequeiro foram IAC 25, IAC 165, IAPAR 9, Guarani e Carajás, do grupo I; e Primavera, CNA 8983, IAC 202, Bonança, Carisma e Canastra, dos grupos III, V e VI, por apresentarem uma série de caracteres de interesse, como precocidade, altos rendimentos e ampla estabilidade e adaptabilidade às diferentes condições ambientais de sequeiro para os cultivares do grupo I e os que integram os grupos III, V e VI. Além dessas características, esses grupos apresentam tipo de grão agulhinha, fator de grande importância na liberação dos cultivares.

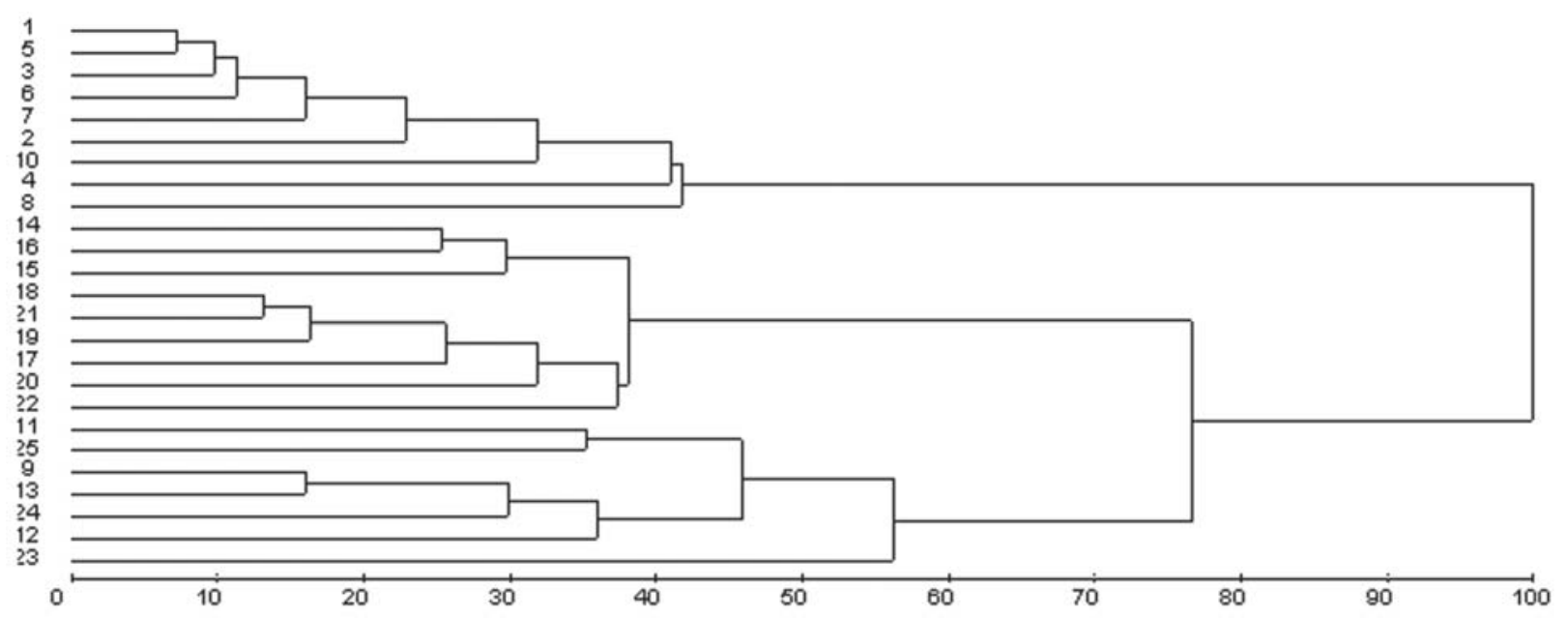

Figura 1 - Dendrograma mostrando o relacionamento de 25 cultivares de arroz em cultivo de sequeiro, obtido pelo método hierárquico do vizinho mais próximo, com base na distância de Mahalanobis.

Rev. Ceres, Viçosa, v. 57, n.1, p. 053-059, jan/fev, 2010 


\section{CONCLUSÕES}

Os caracteres que mais influenciaram a produtividade foram grãos por panícula, percentagem de grãos estéreis e peso do grão.

As cultivares Guarani e Bico Ganga foram as mais divergentes geneticamente e as cultivares Amarelão e IAC 25, as mais similares.

\section{AGRADECIMENTOS}

O presente trabalho foi realizado com o apoio do Conselho Nacional de Desenvolvimento Científico e Tecnológico-CNPq-Brasil e da Universidade Federal de Viçosa-UFV, Viçosa-MG.

\section{REFERÊNCIAS}

Coimbra JLM \& Carvalho FIF (1998) Divergência genética em feijão (Phaseolus vulgaris L) com grão tipo carioca. Revista Brasileira de Agrociencia, 4: 211-217.

Cruz CD (1990) Aplicação de algumas técnicas multivariadas no melhoramento de plantas. Tese de Doutorado. Escola Superior de Agricultura Luiz de Queiroz, Piracicaba, 188p.

Cruz CD (2001) Programa genes: versão Windows; aplicativo computacional em genética e estatística. Viçosa, Ed. UFV. $648 \mathrm{p}$

Cruz CD \& Regazzi A (1997) Modelos biométricos aplicados ao melhoramento genético. Viçosa, Ed. UFV. 390p.

Falconer DS (1981) Introdução à genética quantitativa. Viçosa, Ed. UFV. 279p.
Ferrão MAG, Vieira C, Cruz CD \& Cardoso AA (2002) Genetic divergence on common bean under tropical winter conditions. Pesquisa Agropecuária Brasileira, 371: 1089-1098.

Fuzatto SR, Ferreira DF, Ramalho MAP \& Ribeiro PHE (2002) Divergência genética e sua relação com os cruzamentos dialéticos na cultura do milho. Ciência e Agrotecnologia, 26: 22-32.

Lúcio AD, Storck L \& Banzatto DA (1999) Classificação dos experimentos de competição de cultivares quanto a sua precisão. Pesquisa Agropecuária Gaúcha, 5: 99103.

Machado CF, Nunes GHS, Ferreira DF \& Santos JB (2002) Genetic divergence among genotypes of common bean thought of multivariates techniques. Ciência Rural, 32: 251-258.

Morais OP (1992) Análise multivariada da divergência genética dos progenitores, índice de seleção e seleção combinada numa população de arroz oriunda de intercruzamentos, usando macho-esterilidade. Tese de Doutorado. Universidade Federal de Viçosa, Viçosa, 251p.

Naoe LK, Sediyama CS, Glauco VM, Cruz, CD \& Moreira MA (2001) Parâmetros genéticos estimados em cruzamentos com genitores de diferentes níveis de divergência em soja. In: $1^{\circ}$ Congresso Brasileiro de Melhoramento de Plantas, Goiânia. Anais, EMBRAPA/CNPAF. p.47-48.

Pereira JJ (1999) Análises de agrupamento e discriminante no melhoramento genético: aplicação na cultura do arroz (Oryza sativa L.). Tese de Doutorado. Universidade Federal de Viçosa, Viçosa, 191p.

Reis WP, Vello NA, Ramalho MAP \& Ferreira DF (2001) Divergência genética entre cultivares de trigo recomendados no Brasil nos anos de 1996 e de 1997, In: $1^{\circ}$ Congresso Brasileiro de Melhoramento de Plantas, Goiânia. Anais, EMBRAPA/CNPAF. p.58-59.

Vidigal MCG, Vidigal Filho OS, Amaral Junior AT \& Braccini AL (2001) Divergência genética entre cultivares de mandioca por meio de estatística multivariada. Bragantia, 56: 63-271. 